\title{
Severe herpes simplex virus type-I infections after dental procedures
}

\author{
Lara El Hayderi, Laurent Raty, Valerie Failla, Marie Caucanas, Dilshad Paurobally, Arjen F. Nikkels
}

Department of Dermatology, University Medical Center Liège, Belgium

Correspondence:

Department of Dermatology

University Medical Center of Liège

B-4000 Liège, Belgium.

af.nikkels@chu.ulg.ac.be

Received: 05-01-2010

Accepted: $30-03-2010$
El Hayderi L, Raty L, Failla V, Caucanas M, Paurobally D, Nikkels AF. Severe herpes simplex virus type-I infections after dental procedures. Med Oral Patol Oral Cir Bucal. 2011 Jan 1;16 (1):e15-8. http://www.medicinaoral.com/medoralfree01/v16i1/medoralv16ilp15.pdf

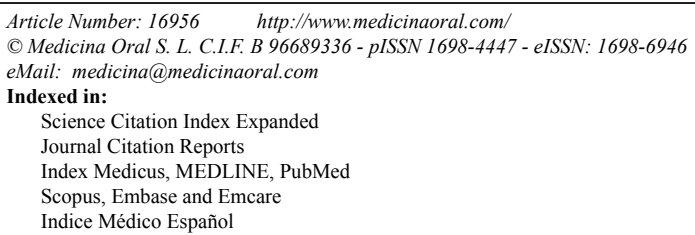

\begin{abstract}
Background: Recurrences of herpes labialis (RHL) may be triggered by systemic factors, including stress, menses, and fever. Local stimuli, such as lip injury or sunlight exposure are also associated to RHL. Dental extraction has also been reported as triggering event.

Case reports: Seven otherwise healthy patients are presented with severe and extensive RHL occurring about 2-3 days after dental extraction under local anaesthesia. Immunohistochemistry on smears and immunofluorescence on cell culture identified herpes simplex virus type I (HSV-I). Five patients reported more severe prodromal signs than usual. Although all the patients suffered from RHL, none had previously experienced RHL after dental care. Two patients required hospitalisation for intravenous acyclovir therapy, whereas the others were successfully treated with oral valaciclovir or acyclovir.

Conclusion: Severe and extensive RHL can occur soon after dental extraction under local anaesthesia. Patients with a previous history of RHL seem to be at higher risk. It is not clear whether RHL is linked to the procedure itself, to the anaesthetic procedure or both. As the incidence is unknown, more studies are required to recommend prophylactic antiviral treatment in RHL patients who are undergoing extractions. Dentists should be aware of this potentially severe post-extraction complication.
\end{abstract}

Key words: Aciclovir, prevention, herpes labialis, triggering factors.

\section{Introduction}

Herpes simplex viruses type I (HSV-I) and II (HSVII) are members of the $\alpha$-herpesvirus family (1). The primary infection establishes a life-long latency in the sensory nerve ganglia. Subsequent infra-clinical recurrences are common, eventually followed by a clinical recrudescence (1). Recurrent herpes labialis (RHL) affects $16 \%$ to $38 \%$ of the population (1). In elderly patients, the frequency of RHL sinks to approximately
$20 \%$. The recrudescence of HSV infections requires simultaneously viral reactivation at the trigeminal ganglia level as well as a cutaneous permissivity allowing intra-epidermal viral replication that lead to lesion formation (1). Recrudescence is usually occurring at the same anatomical site, in general the vermillion border of the upper or lower lip. Recrudescences often present a similar clinical course in terms of duration, pain and lesion severity (1). In many instances, RHL follows 
various initiating events. Systemic stimuli include fever, menses, iatrogenic immunosuppression and stress. Local triggers encompass lip injury, exposure to cold, sunlight, wind, and iatrogenic trauma (1). RHL can also complicate dental procedures, fixed prosthodontic tissue, and surgery of the oral cavity (1-6). Although supposed to be rare, no data on the incidence of dental intervention-associated RHL are available.

Seven patients are described who presented unusual extensive and severe HSV-I infection following dental extraction.

\section{Case Reports}

The salient clinical features of the patients are summarized in table 1 . None of the patients presented a remarkable medical, allergic or surgical previous history. The patients took no immunosuppressive medication. All the patients (3males/4females, mean age: 37.2 years, mininum: 19 years, maximum: 55 years) suffered from longstanding RHL, experiencing between 3 and 8 recrudescences par year. Stress was the most frequent initiating event. Two patients suffered from sun-exposure related recrudescences. Previously, none had experienced RHL after dental care. Five patients systematically recognized the typical prodromal signs, including stinging, burning, dysesthesia, and itching, occurring 1 to 2 days before the recrudescences. Preceding the current episode, the prodromal signs were much more severe than usual.

The patients searched medical advice mainly due to the unusual severity of the eruption. Five patients visited the emergency ward and the others consulted their GP or dermatologist. One of the patients admitted to the emergency ward was initially misdiagnosed as erysipelas and received intravenous antibiotics (Amoxicilline/ clavulinic acid, Augmentin $\AA$, 3x1000mg/day, Smith Kline Beecham). Two patients presented a painful eruption extending to the right cheek, nose, chin, the oral cavity and upper lip (Fig 1,2). Erythematous, vesicular, and crusted lesions were present. Both had fever $\left(39^{\circ} \mathrm{C}\right)$, a regional adenopathy and were not able to eat. Further physical examination was unremarkable. Due to the severity, two patients required hospitalization and intravenous acyclovir $\left(5 \mathrm{mg} / \mathrm{kg} /\right.$ day for 8 days, Zovirax ${ }^{\circledR}$, GSK). Both individuals had a positive past serostatus for HSV (IgG: +, IgM: -). Topical and intraoral disinfection with povidone iodine (Isobetadine $\AA$, MEDA Pharma) was administered three times daily. Blood screening only revealed a mild increase of the sedimentation rate. Other laboratory examinations, including liver, renal, and thyroid functions as well as red and white blood cell counts were in normal range. Serology was negative for HIV, hepatitis A and B.

In the five other patients the eruption extended beyond the usual site of recrudescence to the nasolabial fold, the chin, and the cheek, predominantly affecting the site where the procedure had taken place. The patients were treated with oral valaciclovir (Zelitrex ${ }^{\circledR}, 500 \mathrm{mg}$ b.i.d. for 7 days) or oral acyclovir (5 x $200 \mathrm{mg}$ for 7 days).

All the patients presented the recrudescence 2 to 3 days after the dental interventions. All the procedures (Table 1) were performed under local anaesthesia using lidocaine (either block anaesthesia of the inferior alveolar nerve or local periodontal infiltration for upper molars). The procedures were molar extractions (5), incisor extraction (1) and renewal of a filling (1).

Tzanck smears were performed in 6 patients showing multinucleated, syncytial giant cells and numerous polynuclear neutrophils, suggesting an $\alpha$-herpesvirus infection. Immunohistochemistry using specific antibodies directed against HSV-I, HSV-II and Varicella Zoster Virus (VZV) (7) revealed a positive signal for HSV-I, whereas the other antibodies revealed a negative staining. In one patient, a swab was performed for viral cell culture, revealing HSV-I by immunofluorescence after 48 hours.

The alveolar healing process after extraction was not impaired or delayed.

Two patients required subsequent molar extractions and prophylactic oral valaciclovir (500mg b.i.d., Zelitrex ${ }^{\circledR}$, Glaxo Smith Kline) was administered 48 hours before until three days after dental care. No further herpetic recurrences were observed in both patients. The drug was well tolerated.

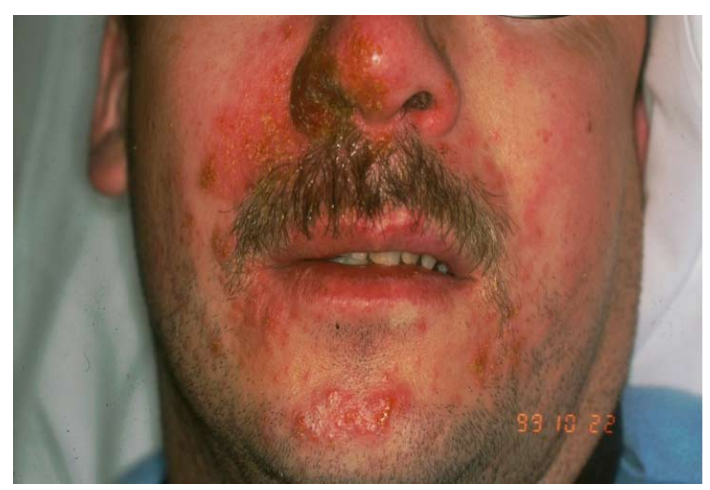

Fig. 1. Severe HSV-I infection following extraction, affecting the lips, cheek, nose, and oral cavity.

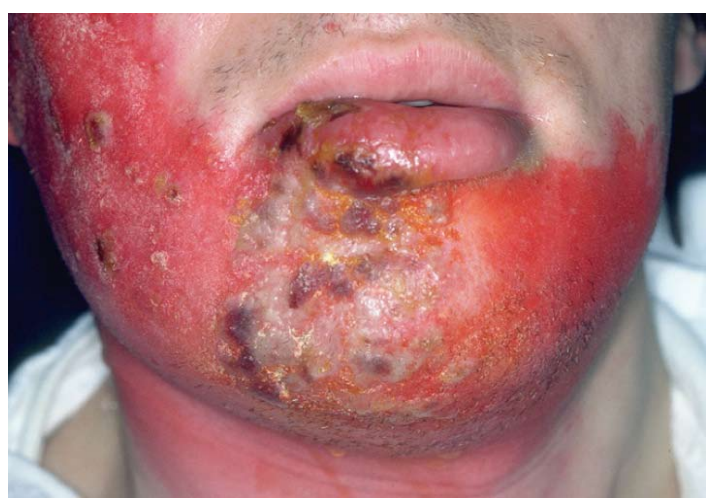

Fig. 2. Severe and extensive HSV-I infection after molar extraction. 
Table 1. Salient patient characteristics.

\begin{tabular}{|c|c|c|c|c|c|c|c|c|}
\hline Case & $\begin{array}{l}\text { Sex } \\
\text { Age }\end{array}$ & Procedure & Anaesthesia & $\begin{array}{c}\text { Time } \\
\text { interval } \\
\text { extraction-RHL }\end{array}$ & Signs & Site & Test & Serology \\
\hline 1 & M 39 & $\begin{array}{l}\text { Extraction } \\
\quad \text { Sup } \\
\text { R 3m }\end{array}$ & Local & $2 d$ & $\begin{array}{l}\mathrm{Fe}, \\
\mathrm{Ad}\end{array}$ & $\begin{array}{l}\text { Labial inf/sup } \\
\text { Cheek, chin }\end{array}$ & $\mathrm{Tz}$ & $\operatorname{IgG}+, \operatorname{IgM}-$ \\
\hline 2 & M 19 & $\begin{array}{l}\text { Extraction } \\
\text { Inf } \\
\mathrm{R} \text { incisor }\end{array}$ & Block & $2 d$ & $\begin{array}{l}\mathrm{Fe}, \\
\mathrm{Ad}\end{array}$ & $\begin{array}{l}\text { Labial inf/sup } \\
\text { Cheek, chin }\end{array}$ & $\mathrm{Tz}$ & IgG+, IgM- \\
\hline 3 & F 55 & $\begin{array}{l}\text { Extraction } \\
\text { Inf } \\
\text { R } 2 \mathrm{~m}\end{array}$ & Block & $2 d$ & - & $\begin{array}{c}\text { Labial sup } \\
\text { Chin Nasolabial }\end{array}$ & $\mathrm{CC}$ & NA \\
\hline 4 & F 21 & $\begin{array}{l}\text { Filling } \\
\text { Sup } \\
\text { R } 1 \mathrm{~m}\end{array}$ & Local & $3 \mathrm{~d}$ & - & $\begin{array}{c}\text { Labial sup } \\
\text { Chin Nasolabial }\end{array}$ & ND & NA \\
\hline 5 & F 30 & $\begin{array}{c}\text { Extraction } \\
\text { Inf } \\
\text { L 3m }\end{array}$ & Block & $3 \mathrm{~d}$ & - & Labial inf/sup & $\mathrm{Tz}$ & IgG+, IgM- \\
\hline 6 & M 46 & $\begin{array}{l}\text { Extraction } \\
\text { Inf } \\
\text { R 3m }\end{array}$ & Block & $2 d$ & - & Labial inf/sup & $\mathrm{Tz}$ & NA \\
\hline 7 & F 51 & $\begin{array}{l}\text { Extraction } \\
\quad \text { Inf } \\
\text { R } 2 \mathrm{~m}\end{array}$ & Block & $3 d$ & - & $\begin{array}{l}\text { Labial inf } \\
\text { Chin, cheek }\end{array}$ & $\mathrm{Tz}$ & $\operatorname{IgG}+, \operatorname{IgM}-$ \\
\hline
\end{tabular}

M: Male, F: Female, Fe: Fever, Ad: Loco-regional adenopathy, Tz: Tzanck smear test, CC: cell culture, Inf: inferior, Sup: superior, R: right, L: left, m: molar, d: days, NA: not available.

\section{Discussion}

Seven cases of severe dental-extraction-related HSV infections are presented. The imputability to dental injury should be taken with precaution. Nevertheless, all the patients had a previous history of RHL, no history of RHL following dental fillings, no RHL at the time of extraction, a significantly more severe eruption than usual, local anaesthesia, a time-interval of 2-3 days, and an increased healing time of the eruption in common. All the recrudescences started at the site of prior episodes. Although dental extraction is usually incriminated as initiating factor, HSV may also complicate fixed prosthodontic tissue (4). There are no data concerning other common dental procedures, such as fillings or removal of dental plaque. Data on frequency of extraction-related RHL are sparse and contradictory. In a study, $4 / 20$ patients with a previous history of RHL experienced RHL after dental extraction whereas no recurrences were noted in 19 patients without a history of RHL (2). However, in a large study evaluating the post-extraction complications of 3818 extractions, no single case of HSV was evidenced (8). In another study comprising 48 patients undergoing third molar extraction showed that the frequency of HSV-1 positive nested polymerase chain reaction (PCR) was low $(4,2 \%)$ and not statistically significant with a control group undergoing conventional procedures (5)
The triggering may be multi-factorial. First, it has been demonstrated that fear and stress for dental procedures increases HSV asymptomatic shedding (9). This may be further increased by the nerve injury during extraction (9). In fact, during surgical procedures involving the trigeminal nerve root, HSV reactivation occurs in up to $50 \%$ of the patients (10). However, HSV shedding seems to occur independently from clinical recurrences $(11,12)$. Third, nerve irritation by the anaesthetic block may also conduct to viral reactivation and recrudescence, as the inferior alveolar nerve is a branch of the mandibular nerve, which is itself the third branch of the trigeminal nerve, where viral latency is established. These three elements probably lead to a higher viral load, explaining the increased severity of the eruption. Extension of HSV cutaneous extension is often facilitated by keratinocytic injury, observed during deep chemical peelings, abrasive laser resurfacing, dermabrasion and other cosmetic procedures (13). These procedures systematically require a prophylactic antiviral treatment (13). However, no signs of prior skin injury were present in the patient. It is unclear, whether the manipulation and extension of the lips during the dental procedure constitutes a risk factor.

The alveolar healing process after extraction seems not delayed or impaired.

The clinical diagnosis of extraction-related RHL is usu- 
ally evident. However, immunohistochemical confirmation on a Tzanck smear is suggested (7), in particular as post-extraction herpes zoster has been described $(14,15)$. As sero-prevalence achieves 90 to $95 \%$ in the adult population, serology is not a recommended diagnostic method.

The treatment of these extraction-related HSV infections relies on oral or intravenous antiviral therapy, according to the clinical severity. In two patients, prophylactic antiviral treatment was effective as no RHL was observed after subsequent molar extractions under local anaesthesia. More data is however required to recommend prophylactic antiviral therapy. Currently, only selected individuals with a history of RHL are eligible for antiviral prophylaxis. In analogy to prophylactic antiviral treatment for abrasive cosmetic procedures, the following scheme could be proposed; oral valaciclovir (500mg b.i.d., Zelitrex ${ }^{\circledR}$, Glaxo Smith Kline), 48 hours before until three days after dental care. Famciclovir or acyclovir may also be considered (13).

In conclusion, recrudescence of HSV can be triggered by dental extraction. These infections seem to be more severe than usual outbreaks. Data on incidence are lacking. Prophylactic antiviral treatment could be considered for RHL patients on an individual basis. Dentists should be aware of this potentially severe complication of dental extraction.

\section{References}

References with links to Crossref - DOI

1. Nikkels AF, Pièrard GE. Treatment of mucocutaneous presentations of herpes simplex virus infections. Am J Clin Dermatol. 2002;3:475-87.

2. Openshaw H, Bennett HE. Recurrence of herpes simplex virus after dental extraction. J Infect Dis. 1982;146:707.

3. Scott DA, Coulter WA, Lamey PJ. Oral shedding of herpes simplex virus type 1: a review. J Oral Pathol Med. 1997;26:441-7.

4. Williamson RT. Diagnosis and management of recurrent herpes simplex induced by fixed prosthodontic tissue management: a clinical report. J Prosthet Dent. 1999;82:1-2.

5. Marques-Silva L, Castro WH, Gomez EL, Guimarães AL, Silva MS, Gomez RS. The impact of dental surgery on HSV-1 reactivation in the oral mucosa of seropositive patients. J Oral Maxillofac Surg. 2007;65:2269-72.

6. Guggenheimer J, Fletcher RD. Traumatic induction of an intraoral reinfection with herpes simplex virus. Report of a case. Oral Surg Oral Med Oral Pathol. 1974;38:546-9.

7. Nikkels AF, Debrus S, Sadzot-Delvaux C, Piette J, Rentier B, Piérard GE. Immunohistochemical identification of varicella-zoster virus gene 63-encoded protein (IE63) and late (gE) protein on smears and cutaneous biopsies: implications for diagnostic use. J Med Virol. 1995;47:342-7.

8. Simon E, Matee M. Post-extraction complications seen at a referral dental clinic in Dar Es Salaam, Tanzania. Int Dent J. 2001;51:273-6. 9. Hyland PL, Coulter WA, Abu-Ruman I, Fulton CR, O'Neill HJ, Coyle PV, et al. Asymptomatic shedding of HSV-1 in patients undergoing oral surgical procedures and attending for noninvasive treatment. Oral Dis. 2007;13:414-8.

10. Pazin GJ, Ho M, Jannetta PJ. Reactivation of herpes simplex virus after decompression of the trigeminal nerve root. J Infect Dis. 1978;138:405-9.

11. Knaup B, Schünemann S, Wolff MH. Subclinical reactivation of herpes simplex virus type 1 in the oral cavity. Oral Microbiol Immunol. 2000;15:281-3.

12. Da Silva LM, Guimarães AL, Victória JM, Gomes CC, Gomez RS. Herpes simplex virus type 1 shedding in the oral cavity of seropositive patients. Oral Dis. 2005;11:13-6.

13. Nestor MS. Prophylaxis for and treatment of uncomplicated skin and skin structure infections in laser and cosmetic surgery. J Drugs Dermatol. 2005;4:s20-5.

14. Maini S, Preece M. Herpes zoster oticus following mandibular block. J Laryngol Otol. 2000;114:212-3.

15. Van Gemert JT, Koole R. [An unusual skin disorder after tooth extraction]. Ned Tijdschr Tandheelkd. 2007;114:98-103. 